\title{
The modular cross-synaptic nature of LTP/LTD following on-going neural activity
}

\author{
Alex Loebel ${ }^{1{ }^{*} \dagger}$, Jean-Vincent Le Bé2† ${ }^{2 \dagger}$ Magnus JE Richardson ${ }^{3}$, Andreas Herz $^{1}$, Henry Markram² \\ From Twentieth Annual Computational Neuroscience Meeting: CNS*2011 \\ Stockholm, Sweden. 23-28 July 2011
}

While synaptic efficacies are modified continuously by on-going spiking activity, it is yet unclear whether the underlying pre- and post-synaptic processes occur independently, or in accordance. To elucidate the effects of sustained spiking communication on synaptic properties, we patch-clamped paired pyramidal neurons in-vitro at both ends of $12 \mathrm{~h}$ intervals of spontaneous or glutamateinduced spiking activity. We found that the synaptic efficacies either increased, or decreased, with the ratio between the second and first measurement ranging between 0.08-14. Using quantal and failure analyses we show that this slow form of long-term potentiation and depression is explained by changes in the estimated number of release sites, alongside overall post-synaptic changes that maintain the quantal size per release site. Our findings suggest that sustained neural activity results in matched pre- and post-synaptic modifications, in which elementary modules that span the synaptic cleft are added or subtracted as a function of experience.

\section{Author details}

${ }^{1}$ Department Biologie II, LMU, and Bernstein Center Munich, Germany. ${ }^{2}$ Brain Mind Institute, Ecole Polytechnique Federale de Lausanne (EPFL), Lausanne, Switzerland. ${ }^{3}$ Warwick Systems Biology Centre, University of Warwick,

Coventry, UK.

Published: 18 July 2011

doi:10.1186/1471-2202-12-S1-01

Cite this article as: Loebel et al:: The modular cross-synaptic nature of LTP/LTD following on-going neural activity. BMC Neuroscience 201112 (Suppl 1):01.
Submit your next manuscript to BioMed Central and take full advantage of:

- Convenient online submission

- Thorough peer review

- No space constraints or color figure charges

- Immediate publication on acceptance

- Inclusion in PubMed, CAS, Scopus and Google Scholar

- Research which is freely available for redistribution
() Biomed Central

\footnotetext{
+ Contributed equally

${ }^{1}$ Department Biologie II, LMU, and Bernstein Center Munich, Germany

Full list of author information is available at the end of the article
} 